\title{
Combination (5\% Hydroquinone, 0.1\% Tretinoin and 1\% Hydrocortisone) Cream in Treating Facial Hyperpigmentation: A Retrospective Patient Satisfaction Survey
}

\author{
John Fleming*, Saqib Bashir \\ Dermatology Department, King's College Hospital, London, UK \\ Email: ${ }^{\text {jdfleming@gmail.com }}$
}

Received 10 September 2014; revised 25 October 2014; accepted 7 November 2014

Copyright (C) 2014 by authors and Scientific Research Publishing Inc.

This work is licensed under the Creative Commons Attribution International License (CC BY). http://creativecommons.org/licenses/by/4.0/

(c) (i) Open Access

\begin{abstract}
Background: Melasma and post-inflammatory hyperpigmentation provide a significant source of psychosocial morbidity, especially in those with Fitzpatrick skin types III-VI. In Europe, a proprietary product aimed at treating these conditions, similar to Kligman's formula but with a longer expiry date, has become available. Objectives: To assess patient satisfaction with a newly available combination de-pigmenting preparation. Methods: We conducted a small study to see if patients felt that this new product affected their quality of life and skin symptoms from hyperpigmentation. 41 subjects, who had all been prescribed a $15 \mathrm{~g}$ tube to use sparingly at night for 90 days within the last 12 months were telephoned to rate the effect the cream had on their quality of life and skin symptom improvement. Each patient also had their Dermatology Life Quality Index (DLQI) score assessed. Results: Out of the 29 patients who responded to the study, 22 had melasma and 7 had post-inflammatory hyperpigmentation from acne. 21 subjects felt that the cream made either a marked or moderate improvement on their quality of life and 23 subjects felt that the cream made either a marked or moderate improvement on their skin symptoms. Conclusion: Patients reported improvement in both hyperpigmentation and quality of life, suggesting a high level of satisfaction with treatment. The long shelf life of the product may also promote compliance and reduce health- care costs.
\end{abstract}

\section{Keywords}

Melasma, Chloasma, Acne-Scarring, Hydroquinone, Tretinoin, Kligman's Solution

\footnotetext{
"Corresponding author.
}

How to cite this paper: Fleming, J. and Bashir, S. (2014) Combination (5\% Hydroquinone, 0.1\% Tretinoin and $1 \%$ Hydrocortisone) Cream in Treating Facial Hyperpigmentation: A Retrospective Patient Satisfaction Survey. Journal of Cosmetics, Dermatological Sciences and Applications, 4, 329-331. http://dx.doi.org/10.4236/jcdsa.2014.45043 


\section{Introduction}

Melasma and post-inflammatory hyperpigmentation provide a significant source of psychosocial morbidity, especially in those with Fitzpatrick skin types III-VI. Kligman's formula was the mainstay of topical depigmenting therapy but occasionally induced skin irritation [1]. Further, it has a short shelf life and high cost, when compounded to order by pharmacists. In Europe, a proprietary product, with a long expiry date, has become available, which may influence treatment effectiveness by reduced cost manufacture from compounding and increased patient use as a result of the longer shelf life. Its ingredients, hydroquinone $5 \%$, tretinoin $0.1 \%$ and hydrocortisone $1 \%$, are similar to Kligman's formula.

\section{Methods}

We studied the effect the proprietary cream had in improving a patient's quality of life and the symptoms they experienced from their skin. 41 subjects, who had all been prescribed a $15 \mathrm{~g}$ tube to use sparingly at night for 90 days within the last 12 months were telephoned to rate the effect the cream had on their quality of life and skin symptom (subjective hyperpigmentation assessment) improvement. They were each asked to rate this as either a marked, moderate or mild improvement or as no improvement. Each patient also had their Dermatology Life Quality Index (DLQI) score assessed.

\section{Results}

The mean post treatment DLQI was 4.4 (range 1 - 10). Those patients deriving the most benefit from the treatment were those making a $15 \mathrm{~g}$ tube last 60 days or more. Of the 7 patients reporting skin irritation and peeling following use, [5] had finished a $15 \mathrm{~g}$ tube of cream in less than 30 days (Figure 1).

\section{Discussion}

Melasma and post-inflammatory facial acne scarring are notoriously difficult conditions to treat. Topical agents, superficial chemical skin peels or laser treatment, are often required to attempt to reduce the appearances of hyperpigmentation. Laser treatment has significant risks of worsening hyperpigmentation, especially in darker skin types III-VI. Other agents in addition to photo and oestrogen avoidance to managemelasma include topical methimazole [2], oral tranexamic acid [3], kojic acid [4] and mulberry [5] (Morus alba). Patients in our study reported improvement in both skin symptoms $(92 \%)$ and quality of life $(88 \%)$, suggesting a high level of satis-

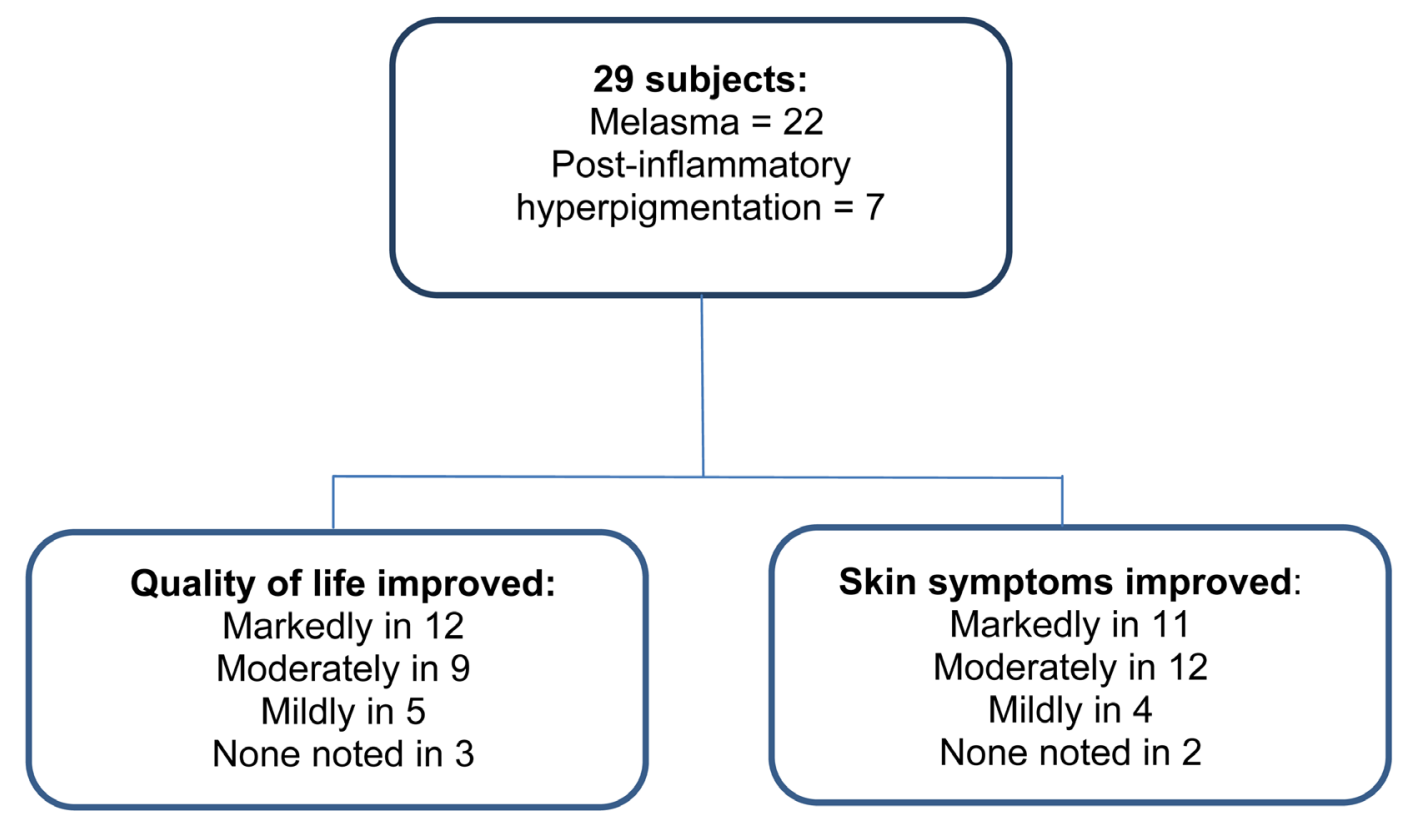

Figure 1. Consort diagram results summary. 
faction with treatment. The advantages of the long shelf life product may also include decreased cost via decreased physician and pharmacist time. The data collected indicate that treatment with the new product effectively improves self-assessed quality of life and hyperpigmentation.

\section{References}

[1] Ball Arefiev, K.L. and Hantash, B.M. (2012) Advances in the Treatment of Melasma: A Review of the Recent Literature. Dermatologic Surgery, 38, 971-984. http://dx.doi.org/10.1111/j.1524-4725.2012.02435.x

[2] Malek, J., Chedraoui, A., Nikolic, D., Barouti, N., Ghosn, S. and Abbas, O. (2013) Successful Treatment of Hydroquinone-Resistant Melasma Using Topical Methimazole. Dermatologic Therapy, 26, 69-72. http://dx.doi.org/10.1111/j.1529-8019.2012.01540.x

[3] Tse, T.W. and Hui, E. (2013) Tranexamic Acid: An Important Adjuvant in the Treatment of Melasma. Journal of Cosmetic Dermatology, 12, 57-66 http://dx.doi.org/10.1111/jocd.12026

[4] Sheth, V.M. and Pandya, A.G. (2011) Melasma: A Comprehensive Update: Part II. Journal of the American Academy of Dermatology, 65, 699-714. http://dx.doi.org/10.1016/j.jaad.2011.06.001

[5] Alvin, G., Catambay, N., Vergara, A. and Jamora, M.J. (2011) A Comparative Study of the Safety and Efficacy of 75\% Mulberry (Morus alba) Extract Oil versus Placebo as a Topical Treatment for Melasma: A Randomized, Single-Blind, Placebocontrolled Trial. Journal of Drugs in Dermatology, 10, 1025-1031. 
Scientific Research Publishing (SCIRP) is one of the largest Open Access journal publishers. It is currently publishing more than 200 open access, online, peer-reviewed journals covering a wide range of academic disciplines. SCIRP serves the worldwide academic communities and contributes to the progress and application of science with its publication.

Other selected journals from SCIRP are listed as below. Submit your manuscript to us via either submit@scirp.org or Online Submission Portal.
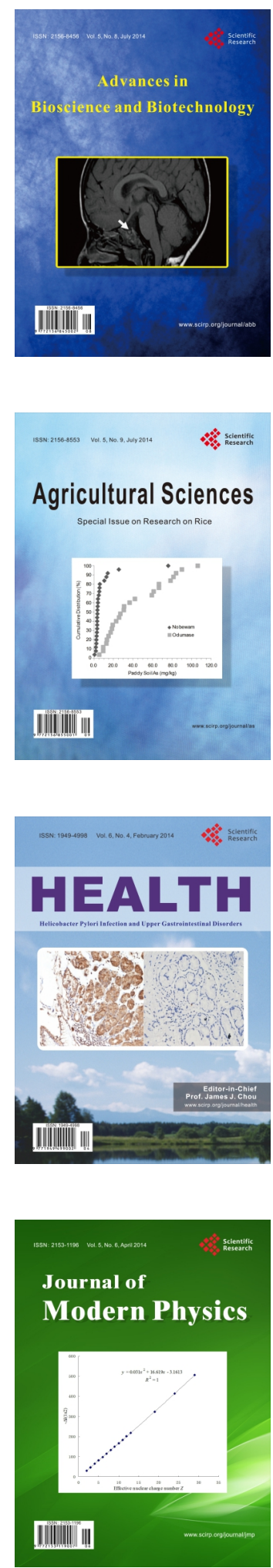
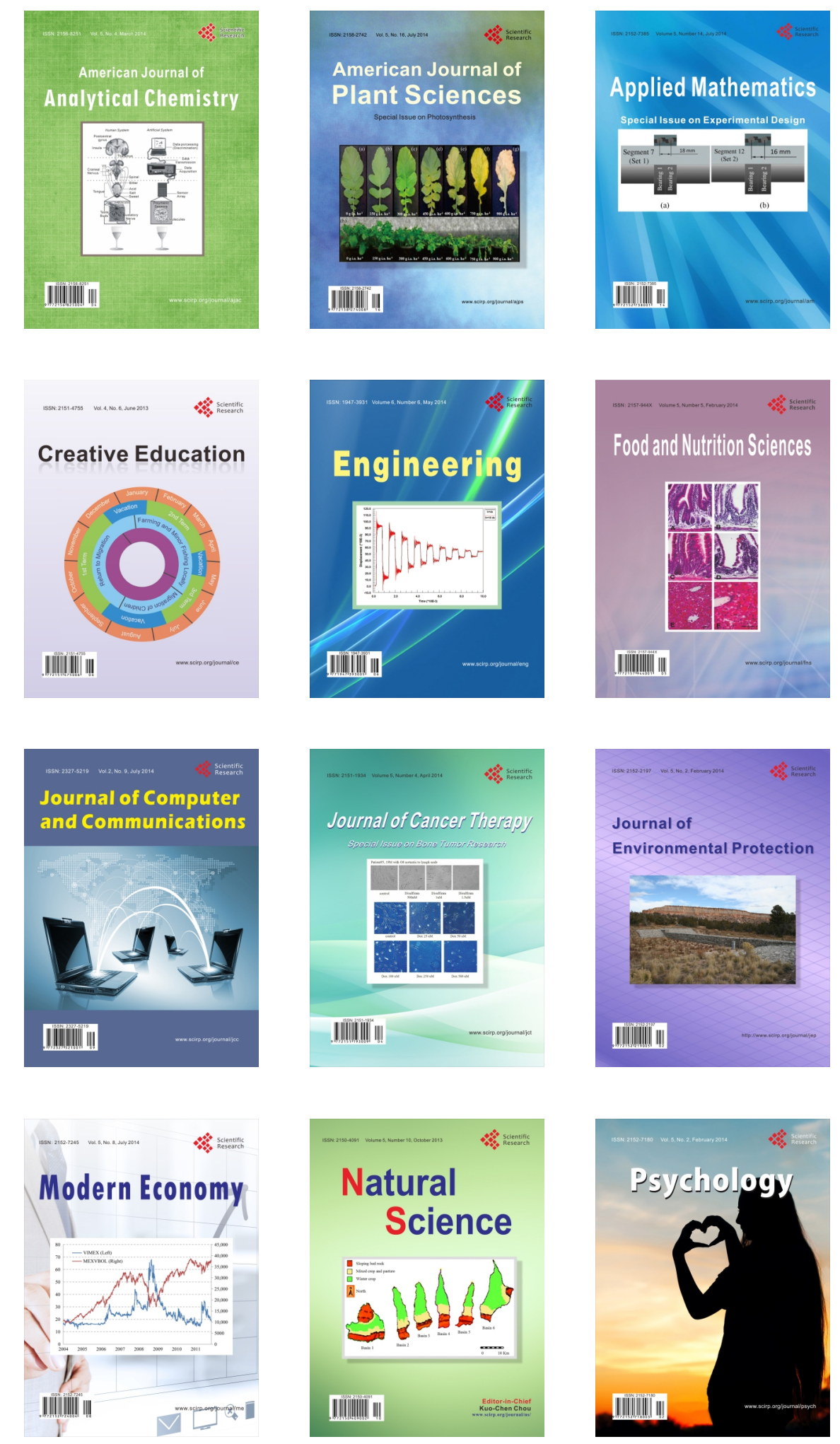